\title{
Statistical Analysis on Field Penetration Index in Shield TBM
}

\author{
Hang-Lo Lee ${ }^{1}$, Dae-Soo Lee ${ }^{2}$, Ki-Il Song1 \\ ${ }^{1}$ Inha University \\ Inha-ro 100, Nam-gu, Incheon, Korea \\ Dwighthaward@naver.com; Ksong@inha.ac.kr \\ ${ }^{2}$ Korea Electric Power Research Institute \\ Munji-ro 105, Yuseong-gu, Deajeon, Korea \\ Leeds400@kepco.co.kr;
}

\begin{abstract}
The prediction of TBM (Tunnel Boring Machine) performance is very important for reliable estimation of construction period and cost in preconstruction stage. TBM performance can be diversely expressed in terms of penetration rate (PR), advance rate (AD) and field penetration index (FPI) etc. To predict the TBM performance more accurately, many researchers have been trying to utilize ground information obtained from field as well as machine data such as RPM, thrust and torque etc. Among the TBM performance, FPI can be used to not only evaluate the rock mass boreability without the influence of TBM operating parameters (Thrust, RPM) in design stage but also to calculate the PR. In this study, various rockmass parameters of shield TBM were analyzed to derive the significant parameters influencing on the FPI and to develop the best predictive model. Rockmass parameters such as water absorption (Wa), deformation modulus (Dm), lugeon value (Lv), rock mass rating (RMR), rock quality designation (RQD) and uniaxial compressive strength (UCS) were obtained from the cable tunnel project in South Korea. After selecting some of rockmass parameters representing the each characteristics of rock and rockmass through a literature review, a simple regression analysis was performed to eliminate some of abnormal data. And then, multiple linear regression analysis was carried out with the selected rockmass parameters (e.g. Lv, RMR and UCS). All of combination of input parameters were analyzed to select the best predictive model which correspond to the lowest PRESS. As a results of the regression analysis, adjusted $r$ squared $\left(\mathrm{R}_{\mathrm{adj}}^{2}\right)$ and mean absolute percentage error (MAPE) were obtained as 0.574 and $32.7 \%$ each other, which means the selected model can be evaluated with explanatory power of $57.4 \%$ and prediction error of $32.7 \%$. However, it should be noted that the developed model is very limited resulting from a narrow range of field data used in this study. Thus, quite a more and a wide range of data are required to develop the universal model.
\end{abstract}

Keywords: TBM performance, Field penetration index, Rockmass parameters, Multiple linear regression analysis

\section{Introduction}

A prediction of shield TBM performance is prerequisite for reliable estimation of construction period and cost in design stage. Among the TBM performance, field penetration index (FPI) can be used to not only evaluate the rock mass boreability without the influence of TBM operating parameters (Thrust, RPM) in design stage but also to calculate the PR. However, it is not easy to predict a FPI theoretically due to the uncertainty and heterogeneity of ground. In this study, various rockmass parameters of shield TBM were analyzed to derive the significant parameters influencing on the FPI and to develop the best predictive model.

\section{Description of field and shield TBM}

In Korea, shield TBM has been widely used to construct cable tunnels. The type of ground used in this field consists of biotite banded gneiss which is soft and partly intrusive rock in Precambrian age. Uniaxial compressive strength (UCS) has a range from $20 \mathrm{Mpa}$ to $95 \mathrm{Mpa}$ and rock quality designation (RQD) were $47 \sim 100 \%$ in soft rock layer. In this study, Six rockmass parameters such as water absorption (Wa), deformation modulus (Dm), Lugeon value (Lv), rock mass rating (RMR), rock quality designation (RQD) and uniaxial compressive strength (UCS)) were collected from field as initial input parameters for prediction of FPI. A descriptive statistics for six rockmass parameters is represented in Table. 1. A TBM used in this cable tunnel is the EPB type shield TBM of $3 \mathrm{~m}$ diameter and more details for TBM specification are also summarized in Table. 2. 
Table. 1: A descriptive statistics for six rockmass parameters collected from this field.

\begin{tabular}{|l|l|l|l|l|l|l|}
\hline \multicolumn{1}{|c|}{ Parameter } & \multicolumn{1}{c|}{ N } & \multicolumn{1}{c|}{ Range } & \multicolumn{1}{c|}{ Min } & \multicolumn{1}{c|}{ Max } & \multicolumn{1}{c|}{ Mean } & \multicolumn{1}{c|}{ Std } \\
\hline UCS (Mpa) & 23 & 75.1 & 20.2 & 95.3 & 50.5 & 21.3 \\
\hline RQD (\%) & 23 & 53.0 & 47.0 & 100.0 & 75.6 & 18.3 \\
\hline RMR (\%) & 23 & 30.0 & 54.0 & 84.0 & 67.7 & 8.6 \\
\hline Wa & 23 & 2.79 & 0.12 & 2.91 & 0.54 & 0.69 \\
\hline Dm (Mpa) & 23 & 62215.0 & 14821.0 & 77036.0 & 40386.3 & 18170.4 \\
\hline Lv & 23 & 15.9 & 0.0 & 15.89 & 2.1 & 3.47 \\
\hline
\end{tabular}

Table. 2: A summary of TBM specification used in this field.

\begin{tabular}{|l|l|}
\hline \multicolumn{1}{|c|}{ Specification } & \multicolumn{1}{c|}{ Value } \\
\hline Machine type & EPB type shield TBM \\
\hline Machine diameter & $\emptyset 3.0 \mathrm{~m}$ \\
\hline Excavation diameter & $\varnothing 3.6 \mathrm{~m}$ \\
\hline Total thrust & $9600 \mathrm{KN}(800 \mathrm{KN} / \mathrm{unit} \times 12 \mathrm{unit})$ \\
\hline Cutterhead torque & $1250 \mathrm{KN} \cdot \mathrm{m}$ \\
\hline Cutterhead revolution per minute & $0.0 \sim 9.0 \mathrm{RPM}$ \\
\hline The number of cutters & $31(\varnothing 0.35 \mathrm{~m})$ \\
\hline
\end{tabular}

\section{Selection of rockmass parameters through literature review}

To select the main parameters representing each characteristics of rock and rockmass, three categories were made in terms of rock strength, joint characteristics and permeability. In the case of rock strength, it is well known that a UCS has a decisive influence on TBM performance [4]. It also can replace Dm due to a close correlation with Dm [3]. Therefore, it was concluded that a UCS was determined as a main factor to represent the rock strength. In joint characteristics, there are two parameters such as RMR and RQD. RMR is a comprehensive parameter expressing various characteristics of rockmass for example, joint spacing, joint condition, joint orientation and so on. According to [1], the rock mass fracturing is the most important penetration rate (PR) parameter for tunnel boring. Rock mass fracturing is characterized by degree of fracturing (type and spacing) and the angle between the tunnel axis and the planes of weakness. Also, the value of RQD is partially included to calculate RMR. For this reason, RMR was determined to represent the category of joint characteristics. Lastly, Lv and Wa might be included in the category of permeability. Lv is defined as the loss of water in litres per minute and per metre borehole at an overpressure of $1 \mathrm{MPa}$. It has been not used as factor of TBM performance so far [5], however, Lv was selected as a representative factor for permeability to investigate whether permeability of rock mass affects the TBM performance or not.

\section{Statistical analysis using field data}

\subsection{Diagnosing the abnormal data}

In the field of statistics, various methods for eliminating abnormal data have been suggested by many researchers. Among them, three measures i.e., outliers, high leverage point and influential point are mainly used to diagnose a data. Information for each measure are summarized in Table. 3. Outlier means an abnormal y value for a given $\mathrm{x}$ point. On the other hand, influential point significantly changes the coefficients of the regression model. However, since an outlier is not always an influential point [6], in this study, it was determined that a data should not be removed simply because of an outlier. To minimize a data loss, therefore, it was determined to eliminate only outliers that are influential as well [2]. Figure. 1 shows a graph for diagnosing the abnormal points using the R programming language [7]. First, the abnormal points for a simple regression model between each rockmass parameter and FPI were removed, and then the abnormal 
points for the multiple linear regression model were removed. Where, plotted red circle correspond to influential point. As a result, it can be seen that the data number 3, 9, 26 and 27 among the total number of 27 were eliminated as the abnormal values.

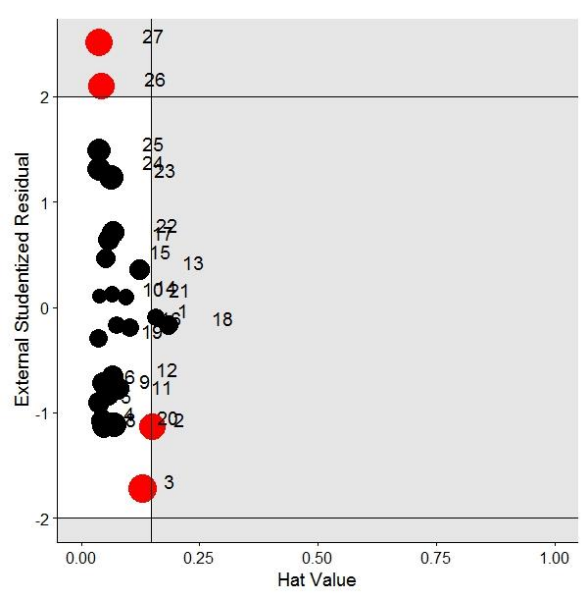

(a) FPI UCS

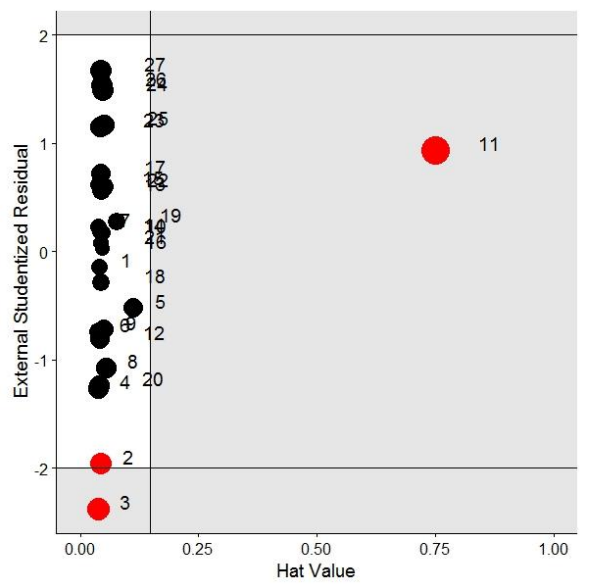

(c) FPI $\sim \mathrm{Lv}$

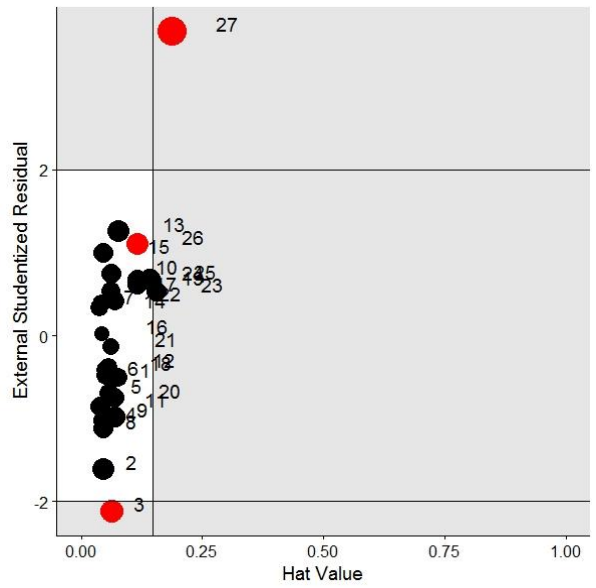

(b) FPI RMR

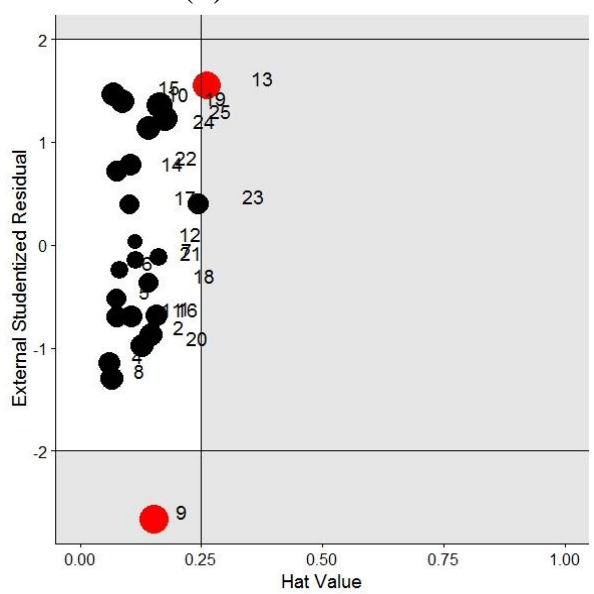

(d) FPI UCS + RMR + Lv

Fig. 1: Graph for diagnosing an abnormal data $(3,9,26$ and 27).

Table. 3: Summary of three measures for diagnosing the abnormal data.

\begin{tabular}{|l|l|l|l|}
\hline Measure & \multicolumn{1}{|c|}{ Definition } & \multicolumn{1}{c|}{ Method } & \multicolumn{1}{c|}{ Criteria for suspected point } \\
\hline Outlier & $\begin{array}{l}\text { The observation which } \\
\text { has unusual y-value for } \\
\text { given its x-point }\end{array}$ & $\begin{array}{l}\text { External studentized } \\
\text { residual }\left(r_{i}^{*}\right)\end{array}$ & $\left|r_{i}^{*}\right|>2.0$ \\
\hline $\begin{array}{l}\text { Leverage } \\
\text { point }\end{array}$ & $\begin{array}{l}\text { The x-point which is } \\
\text { either 2 times higher or } \\
\text { lower than the mean of x- } \\
\text { point }\end{array}$ & Hat matrix value $\left(h_{i i}\right)$ & $\begin{array}{l}h_{i i}>\frac{2 p}{n} \\
\text { Where, } \mathrm{p} \text { is the number of parameter } \\
\text { and } \mathrm{n} \text { is the number of dataset }\end{array}$ \\
\hline $\begin{array}{l}\text { Influential } \\
\text { point }\end{array}$ & $\begin{array}{l}\text { The observation which } \\
\text { changes the coefficient of } \\
\text { the model significantly }\end{array}$ & DFFITS (DFFITS $\left.)_{\mathrm{i}}\right)$ & $\mid$ DFFITS $_{\mathrm{i}} \mid>2 \sqrt{\frac{p}{n}}$ \\
\hline
\end{tabular}




\subsection{Regression analysis using cross validation}

Using the 23 dataset without abnormal points, a simple regression analysis was performed between UCS, RMR, Lv and FPI. As shown in Table. 4, RMR has the highest $r$ squared (38.9\%) and significance for $p$ value (0.001). This means the FPI can best be described by the RMR. On the other hand, UCS relatively has a poor correlation with FPI.

Table. 4: A summary results of simple regression analysis and $r$ squared.

\begin{tabular}{|l|l|l|l|l|}
\hline \multicolumn{1}{|c|}{ Parameter } & \multicolumn{1}{c|}{ R squared } & \multicolumn{1}{c|}{ P value } & \multicolumn{1}{c|}{ Shape of model } & \multicolumn{1}{c|}{ Relationship } \\
\hline & \multicolumn{2}{|c|}{ FPI } & & \\
\hline UCS & 0.081 & 0.189 & Logarithm & FPI $=8.93 \ln (\mathrm{UCS})-1.901$ \\
\hline RMR & 0.389 & 0.001 & Exponential & FPI $=3.08 \mathrm{e}^{0.033 \mathrm{RMR}}$ \\
\hline LV & 0.111 & 0.097 & Exponential & FPI $=34.17 \mathrm{e}^{-0.050(\mathrm{Lv})}$ \\
\hline
\end{tabular}

In the multiple regression analysis, after generating all combinations of rockmass parameters using R-coding as shown in Table. 5, cross validation was used to evaluate the predictive power of each combination. The procedure for cross validation is that each dataset is tested by a model that fits into all the rest of the data. The overall performance can be expressed as the sum of squared error (PRESS). If the PRESS value is the smallest, the corresponding model indicates the highest predictive performance. As a result, FPI UCS + RMR among various combinations showed the smallest PRESS. The equation and 3D graph are shown in Eqs. (1) and Figure. 2 respectively.

$$
F P I=0.26 U C S+1.222 R M R-63.618 \text { (Adjusted r squared: } 0.574, \mathrm{p} \text {-value: } 0.000076)
$$

Table. 5: Results of predictive power for all of combinations.

\begin{tabular}{|l|l|l|}
\hline \multicolumn{1}{|c|}{ Combination of formula } & \multicolumn{1}{c|}{ Predictive MAPE $(\%)$} & \multicolumn{1}{c|}{ PRESS } \\
\hline FPI $\sim$ UCS & 46.58028 & 4657.87 \\
\hline FPI $\sim$ RMR & 37.61989 & 2844.62 \\
\hline FPI $\sim$ Lv & 46.05860 & 4632.56 \\
\hline FPI $\sim$ UCS + RMR & 32.70236 & 2217.97 \\
\hline FPI $\sim$ UCS + Lv & 47.18222 & 4760.54 \\
\hline FPI $\sim$ RMR + Lv & 37.57577 & 2847.52 \\
\hline FPI $\sim$ UCS + RMR + Lv & 31.94453 & 2230.05 \\
\hline
\end{tabular}

As can be seen in Table. 5, the combination, FPI UCS + RMR + Lv, has the lowest mean absolute percentage error (MAPE), however, there is almost no difference with the Eqs. (1). That means Lv has little effect on the FPI model. Lastly, it should be noted that the developed model, Eqs. (1), is very limited resulting from a narrow range of field data (e.g. UCS has range from 20Mpa to $95.3 \mathrm{Mpa}$ and from 54Mpa to $84 \mathrm{Mpa}$ for RMR). Therefore, quite a more and a wide range of data are required to develop the universal model.

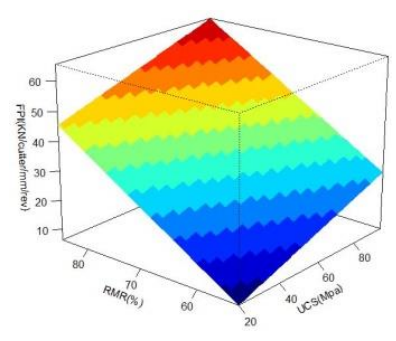




\section{Conclusion}

Fig. 2: A 3D visualization graph for Eqs. (1).

Among the TBM performance, FPI can be used to not only evaluate the rockmass boreability without the influence of TBM operating parameters (Thrust, RPM) in design stage but also to calculate the PR. In this study, various rockmass parameters of shield TBM were analyzed to derive the significant parameters influencing on the FPI and to develop the best predictive model. After selecting some of rockmass parameters representing the each characteristics of rock and rockmass, all of combination of selected parameters were analyzed to make the best predictive model which correspond to the lowest PRESS. As a results of the regression analysis, adjusted $r$ squared $\left(R_{\mathrm{adj}}^{2}\right)$ and mean absolute percentage error (MAPE) were obtained as 0.574 and $32.7 \%$ each other, which means the selected model can be evaluated with explanatory power of $57.4 \%$ and prediction error of $32.7 \%$. Also, it was found that Lv has little effect on the FPI model. However, it should be noted that the developed model is very limited resulting from a narrow range of field data (e.g. UCS has range from $20 \mathrm{Mpa}$ to $95.3 \mathrm{Mpa}$ and from $54 \mathrm{Mpa}$ to $84 \mathrm{Mpa}$ for RMR). Therefore, quite a more and a wide range of data are required to develop the universal model.

\section{Acknowledgements}

This research was supported by a grant (15SCIP-B105148-01) from the Construction Technology Research Program funded by the Ministry of Land, Infrastructure, and Transport of the Korean government.

\section{References}

[1] A. Bruland, "Advance Rate and Cutter Wear. Hard Rock Tunnel Boring Machine," 1998.

[2] D. Cousineau, S. Chartier, "Outliers detection and treatment: a review," International Journal of Psychological Research, vol. 3, no. 1, pp. 58-67, 2015.

[3] D. U. Deere, R. P. Miller, Engineering classification and index properties for intact rock, Illinois university at urban adept of civil engineering, 1996.

[4] Q. M. Gong, J. Zhao, "Development of a rock mass characteristics model for TBM penetration rate prediction," International journal of Rock mechanics and mining sciences, vol. 46, no.3, pp. 8-18, 2009.

[5] H. L. Lee, K. I. Song, G. C. Cho, "Analysis on prediction models of TBM performance: A review," Journal of Korean Tunnelling and Underground Space Association, vol. 18, no. 2, pp. 245-256, 2016.

[6] R. H. Myers, "Classical and modern regression with applications," Boston: PWS and Kent Publishing Company, 1990.

[7] R Core Team, "R: A Language and Environment for Statistical Computing," R Foundation for Statistical computing, Vienna, Austria, 2016. 